\title{
Dietary sodium restriction in the treatment of mild hypertension
}

By P. M. Dodson, M. J. Webeerley and S. P. Waldron, Department of Medicine and Clinical Investigation Unit, Dudley Road Hospital, Birmingham $B \mathbf{8} 7 \mathrm{QH}$

Mild hypertension, defined as a diastolic blood pressure $>95 \mathrm{~mm} \mathrm{Hg}$ and $<\mathrm{ro5}$ $\mathrm{mm} \mathrm{Hg}$ by the World Health Organization (WHO) (1978), has become a therapeutic dilemma. Although controlled clinical trials have shown that drug therapy for mild hypertension protects against stroke, congestive heart failure and progression of hypertension, there is only a spotty effect against coronary artery disease (Hypertension Detection and Follow-up Programme Co-operative Group, 1979; Management Committee of the Australian Therapeutic Trial in Mild Hypertension, 1980; Helgeland, 1980; Multiple Risk Factor Intervention Trial Research Group (MRFIT), I 982). This of course is the most common and serious complication of hypertension. In two of the studies (Helgeland, 1980; MRFIT, 1982) mortality from coronary artery disease was actually increased in some sub-groups of patients treated with anti-hypertensive drug therapy. These findings, along with the rising pressure to treat millions of asymptomatic mildly hypertensive subjects with lifelong drug therapy, have rekindled interest in a nutritional approach to the treatment of hypertension (Kaplan, 1985).

\section{Moderate sodium restriction}

Many studies were performed in the 1970 s demonstrating a hypotensive response to moderate sodium restriction (Parijs et al. 1973; Carney et al. 1975; Magnani et al. 1976; Morgan et al. 1978). However, these studies were often poorly controlled, neither randomized nor blinded and often incorporated diuretic therapy as well.

Two recent studies have been reported which were particularly carefully controlled (MacGregor et al. 1982; Watt et al. 1983). Both these studies were similar in design, with small groups of patients being placed on Na restriction and then randomly allocated in a double-blind crossover manner to either supplementation with $80 \mathrm{mmol} / \mathrm{d}$ of slow-release $\mathrm{Na}$ tablets or to placebo tablets. However, there were subtle differences between the two studies. The study of Watt et al. ( 1983 ) had only a 2 week run-in period, was performed in a general practice setting, used only white Caucasian subjects and the initial mean blood pressure levels were in the normotensive range (according to WHO criteria for hypertension: > $160 / 95 \mathrm{~mm} \mathrm{Hg}$ ). In contrast, the study of MacGregor et al. (1982) had a 2 month run-in period, was performed on hospital out-patients, had 
one-third black patients included in the group, and initial mean blood pressure levels clearly demonstrated mild hypertension.

A synopsis of the contrasting results of these two reports and other recent controlled studies are shown in Table $I$. The average blood pressure fell significantly in the studies of both Watt et al. (1983) and MacGregor et al. (1982) during periods of low $\mathrm{Na}$ intake, but the blood pressures in the latter study returned almost to the pre-study level when sodium chloride was added, whereas the pressures were the same during both the low and high $\mathrm{Na}$ intake periods in the study by Watt et al. (1983).

Therefore, despite very careful control in both studies, contrasting results were found. The explanations for this may well include the differences in study design. The short run-in period used by Watt et al. ( 1983 ) may mean that the equal falls seen in both groups just reflects the non-specific reductions commonly seen over the first $4^{-8}$ weeks of repeated measurements. Furthermore, the initial blood pressure recordings of Watt et al. ( $\mathrm{I}^{9} \mathrm{8}_{3}$ ) were within the normal range, thereby decreasing the likelihood of a response to any form of anti-hypertensive therapy.

Another recent study by Richards et al. (1984) included random allocation of twelve hypertensive patients to a period of normal $\mathrm{Na}$ intake $(180 \mathrm{mmol} / \mathrm{d}$ ) or $\mathrm{Na}$ restriction $(80 \mathrm{mmol} / \mathrm{d})$. Intra-arterial blood pressures were monitored in addition to outpatient recordings. Seven of the twelve patients had some fall of blood pressure on the Na-restricted diet, but the fall in all twelve patients was not significant. These results may reflect a problem with the design of the study with regard to the order of diets given as well as the small number of subjects studied. These results would also seem to confirm the most important observation of others, that there is a 'variable' degree of response to $\mathrm{Na}$ restriction (Longworth $e$ t al. 1980; MacGregor et al. 1982) introducing the concept of salt-sensitive and salt-insensitive subjects. The exact proportion of patients who may be 'salt sensitive' is unfortunately not clear from the literature, with values ranging from 20 to $60 \%$ of the population (Laragh \& Pecker, 1983).

Parallel design studies have also been performed. These include those by Silman et al. (1983), Beard et al. (1982) and, in diabetic hypertensives, by Dodson et al. (1984). The study of Silman et al. (1983) demonstrated significant reductions in blood pressure over a period of $\mathrm{I}$ year in subjects on a low $\mathrm{Na}$ intake, with a mean fall in blood pressure of $9 / 7 \mathrm{~mm} \mathrm{Hg}$ greater than that of controls. However, half the patients did not collect urine samples at 6 or 12 months, making compliance difficult to ascertain and the mean difference in daily urinary $\mathrm{Na}$ excretion between the low and high $\mathrm{Na}$ intake groups was only of the order of $42 \mathrm{mmol}$, a small reduction.

Beard et al. (1982) studied a larger group of hypertensive subjects established on anti-hypertensive medication $(n 90)$ for 3 months during which forty-five subjects reduced their $\mathrm{Na}$ intake to $37 \mathrm{mmol} / \mathrm{d}$. This group demonstrated a greater fall in blood pressure than the control group and were able to discontinue more than $50 \%$ of anti-hypertensive drug therapy. However, the study included multiple nutritional modifications besides $\mathrm{Na}$ restriction, including increasing fibre and 


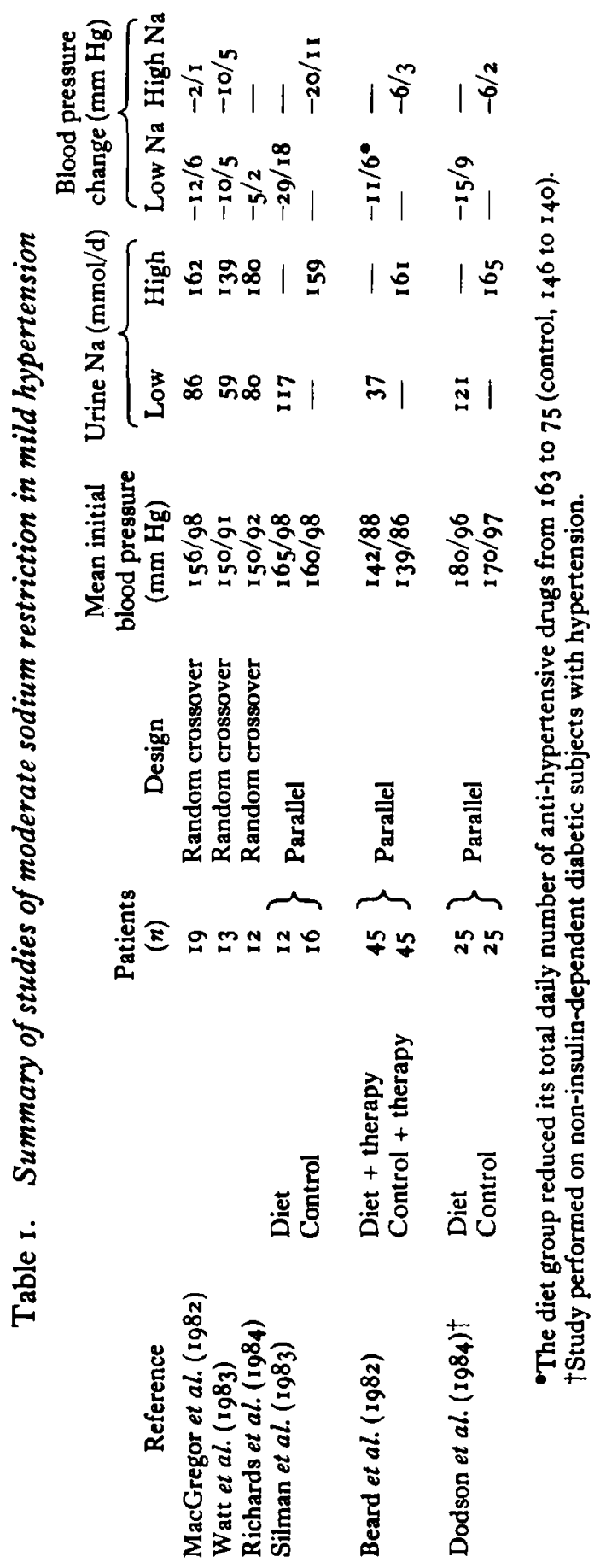


lowering fat intake which in themselves may well have played a role in the hypotensive effect. More attention and time in terms of dietary councelling was also spent with the diet-treated group.

A recent study (Dodson et al. 1984) has also highlighted the theory that mild hypertension associated with diabetes may be $\mathrm{Na}$ sensitive. Fifty hypertensive non-insulin-dependent diabetic subjects were allocated to either a 3 month treatment period incorporating $\mathrm{Na}$ restriction $(n 25)$ or to a control period $(n 25)$. Significant reductions, particularly of diastolic blood pressure were noted but, like that of the study by Beard et al. (1982), multiple nutritional modifications were made. Despite this, multiple regression analysis demonstrated a significant relation between the reduction of urinary $\mathrm{Na}: \mathrm{K}$ value and falls in both systolic and diastolic blood pressure, suggesting that the change in $\mathrm{Na}$ intake may have been, in part, responsible for the blood pressure drop. It is also of interest to note that the reduction in blood pressure by this sort of dietary regimen appears comparable to that observed with conventional anti-hypertensive drug therapy (Pacy et al. $1984 a, b)$.

Another way in which $\mathrm{Na}$ restriction might be beneficial is the potentiation of anti-hypertensive drug therapy. Again results are conflicting. Parijs et al. (1973) demonstrated a significant decrease of blood pressure on all occasions when a thiazide diuretic was given in combination with sodium restriction, but Van Brummelen et al. (1978) demonstrated no such effect. However, a recent well-controlled randomized double-blind trial of $\mathrm{Na}$ restriction in combination with either a $\beta$-blocking agent or a diuretic has reopened this question (Erwteman et al. 1984). For example, although the reduction in blood pressure in patients on a combination of hydrochlorothiazide with $\mathrm{Na}$ restriction was not different from the effect of just hydrochlorothiazide alone, this was not the case for a cardioselective $\beta$-blocking agent. Metoprolol in combination with $\mathrm{Na}$ restriction produced a fall in blood pressure of approximately $28.5 / 17 \mathrm{~mm} \mathrm{Hg}$ compared with $21 \cdot 3 / 12.9 \mathrm{~mm}$ $\mathrm{Hg}$ for the drug alone. The potentiating effect may also become more important with the advent of newer anti-hypertensive drugs, in particular the angiotension-converting enzyme inhibitor group (Captopril and Enalapril) with which increased $\mathrm{Na}$ loss is well known to augment the hypotensive effect (Lant et al. 1984 ).

\section{Palatability and compliance in the long term}

Even if $\mathrm{Na}$ restriction is beneficial in mild hypertension, the importance of palatability and long-term compliance needs to be investigated. Little information is available on this aspect but it does appear that the taste preference for $\mathrm{Na}$ diminishes after 3 months of Na restriction, so that such a diet should become more acceptable with time (Beauchamp et al. 1983). This is supported by the observation in the studies of Beard et al. (1982) and Dodson et al. (1984) in which approximately two-thirds of patients were willing to continue on a $\mathrm{Na}$ restricted diet for the long term.

Evidence for long-term compliance and efficacy of this approach is to be found 
in two recent reports (Dodson et al. $1985 a, b$ ). A group of nineteen patients with essential hypertension were followed up after 4 years on a dietary regimen which included $\mathrm{Na}$ restriction. The results were surprising. A $40 \%$ reduction in anti-hypertensive drug therapy with a significant reduction in blood pressure was observed and dietary history analysis demonstrated good compliance with the diet. However, these observations were made in $50 \%$ of the patients who had originally started the regimen 4 years previously. The second report is of a I year follow-up of a group of fifty diabetic hypertensive subjects treated with a similar regimen. Again a similar reduction in blood pressure was recorded in approximately $60 \%$ of patients.

These preliminary results are therefore encouraging but considerable research is required in this area to assess the feasibility of such a dietary approach for mild hypertension in the community.

\section{Conclusion}

The majority of studies in hypertensive subjects would support the findings that moderate $\mathrm{Na}$ restriction alone has a hypotensive effect in a fair proportion of hypertensive patients and that it may augment the effects of anti-hypertensive drug therapy. Preliminary results on the long-term effects are encouraging. There also appears to be no apparent potential for harm from moderate $\mathrm{Na}$ restriction (Kaplan, I985) to a level of around $100 \mathrm{mmol} / \mathrm{d}$, achieved by deleting very high $\mathrm{Na}$-containing foods from the diet and by not adding salt to food during cooking or at the table.

The authors are most grateful to the staff of the Clinical Investigation Unit and for the support of Drs K. G. Taylor and R. F. Fletcher.

\section{REFERENCES}

Beard, T. C., Cooke, H. M., Gray, W. R. \& Barge, R. (1982). Lancet ii, 455-458.

Beauchamp, G. K., Bertino, M. \& Engelman, K. (1983). Annals of Internal Medicine 98, 763-769. Carney, S., Morgan, T., Wilson, M., Matthews, G. \& Roberts, R. (1975). Medical fournal of Australia 1, 803-807.

Dodson, P. M., Pacy, P. J., Bal, P., Kubicki, A. J., Fletcher, R. F. \& Taylor, K. G. (1984). Diabetologia 27, 522-526.

Dodson, P. M., Pacy, P. J. \& Cox, E. V. ( $\left.\operatorname{Ig}_{5} a\right)$. Human Nutrition: Clinical Nutrition, 39C, 213-220.

Dodson, P. M., Pacy, P. J., Webberley, M. J., Fletcher, R. F. \& Taylor, K. G. (1985b). Proceedings of the Nutrition Society 44, I29A.

Erwteman, T. M., Nagelkerke, N., Lubsen, J., Koster, M. \& Dunning, A. J. (1984). British Medical fournal 289, 406-409.

Helgeland, A. (1980). American fournal of Medicine 69, 725-732.

Hypertension Detection and Follow-up Programme Co-operative Group (1979). Fournal of the American Medical Association 242, 2562-2571.

Kaplan, N. M. (1985). Annals of Internal Medicine 102, 359-373.

Lant, A. F., McNabi, R. W. \& Noormohamed, F. H. (1984). Journal of Hypertension 2, Suppl 2, 37-42.

Laragh, J. H. \& Pecker, M. S. (1983). Annals of Internal Medicine 98, 735-743. 
Longworth, D. L., Drayer, J. I. M., Weber, M. A. \& Laragh, J. H. (1980). Clinical Pharmacology and Therapeutics 27, 544-546.

MacGregor, G. A., Markandu, N., Best, F. E., Elder, D. M., Cam, J. M., Sagnella, G. A. \& Squires, M. (Ig82). Lancet i, 351-354.

Magnani, B., Ambrosioni, E., Agosta, R. \& Racco, F. (1976). Clinical Science and Molecular Medicine 51, Suppl. 3, 6258-626s.

Management Committee of the Australian Therapeutic Trial in Mild Hypertension (1980). Lancet i, $1261-1267$.

Morgan, T., Adam, W., Gillies, A., Wilson, M., Morgan, G. \& Carney, S. (1978). Lancet i, 227-230.

Multiple Risk Factor Intervention Trial Research Group (1982). Fournal of the American Medical Association 248, $1465-1477$.

Pacy, P. J., Dodson, P. M., Kubicki, A. J., Fletcher, R. F. \& Taylor, K. G. (1984a). Fournal of Hypertension 2, $215-220$.

Pacy, P. J., Dodson, P. M., Kubicki, A. J., Fletcher, R. F. \& Taylor, K. G. (1984b). Diabetes Research 1, 201--207.

Parijs, J., Joossens, J. V., Van Der Linden, L., Verstreken, G. \& Amery, A. K. P. C. (1973). American Heart fournal 85, 22-34.

Richards, A. M., Nicholls, M. G., Espiner, E. A., Ikram, H., Maslowski, A. H., Hamilton, E. J. \& Wells, J. E. (1984). Lancet i, 757-761.

Silman, A, J., Locke, C., Mitchell, P. \& Humpherson, P. (1983). Lancet i, I 1 79-1 182.

Van Brummelen, P., Schalekamp, M. \& de Graff, J. (1978). Acta Medica Scandinavica 204, $151-157$.

Watt, G. C. M., Edwards, C., Hart, J. T., Hart, M., Walton, P. \& Foy, C. J. W. (Ig83). British Medical Fournal 286, 432-436.

World Health Organization (1978). Report of a WHO Expert Committee on Hypertension, Technical Report Series, no. 628. Geneva: WHO. 